\title{
A molecular inversion probe-based next-generation sequencing panel to detect germline mutations in Chinese early-onset colorectal cancer patients
}

\author{
Junxiao Zhang ${ }^{1}$, Xiaoyan Wang ${ }^{2}$, Richarda M. de Voer ${ }^{1}$, Jayne Y. Hehir-Kwa ${ }^{1}$, \\ Eveline J. Kamping ${ }^{1}$, Robbert D.A. Weren ${ }^{1}$, Marcel Nelen ${ }^{1}$, Alexander Hoischen ${ }^{1}$, \\ Marjolijn J.L. Ligtenberg ${ }^{1,3}$, Nicoline Hoogerbrugge ${ }^{1}$, Xiangling Yang $^{2}$, Zihuan \\ Yang $^{2}$, Xinjuan Fan ${ }^{4}$, Lei Wang ${ }^{2}$, Huanliang Liu' ${ }^{2,5}$, Jianping Wang ${ }^{2, *}$, Roland P. \\ Kuiper $^{1,6, *}$, Ad Geurts van Kessel ${ }^{1, *}$ \\ ${ }^{1}$ Department of Human Genetics, Radboud University Medical Center, Radboud Institute for Molecular Life Sciences, Nijmegen, \\ The Netherlands \\ ${ }^{2}$ Guangdong Provincial Key Laboratory of Colorectal and Pelvic Floor Diseases, Guangdong Institute of Gastroenterology and the \\ Sixth Affiliated Hospital, Sun Yat-Sen University, Guangzhou, Guangdong, China \\ ${ }^{3}$ Department of Pathology, Radboud University Medical Center, Nijmegen, The Netherlands \\ ${ }^{4}$ Department of Pathology, the Sixth Affiliated Hospital, Sun Yat-Sen University, Guangzhou, Guangdong, China \\ ${ }^{5}$ Department of Clinical Laboratory, the Sixth Affiliated Hospital, Sun Yat-Sen University, Guangzhou, Guangdong, China \\ ${ }^{6}$ Princess Máxima Center for Pediatric Oncology, Utrecht, The Netherlands \\ "These authors contributed equally to this work
}

Correspondence to: Roland P. Kuiper, email: r.kuiper@prinsesmaximacentrum.nl Jianping Wang, email: wangjpgz@126.com

Keywords: molecular inversion probes, early-onset colorectal cancer, Mendelian colorectal cancer predisposition syndromes, next-generation sequencing

Received: June 17, 2016

Accepted: February 12, 2017

Published: February 21, 2017

Copyright: Zhang et al. This is an open-access article distributed under the terms of the Creative Commons Attribution License (CC-BY), which permits unrestricted use, distribution, and reproduction in any medium, provided the original author and source are credited.

\section{ABSTRACT}

The currently known Mendelian colorectal cancer (CRC) predisposition syndromes account for $5-10 \%$ of all CRC cases, and are caused by inherited germline mutations in single CRC predisposing genes. Using molecular inversion probes (MIPs), we designed a targeted next-generation sequencing panel to identify mutations in seven CRC predisposing genes: APC, MLH1, MSH2, MSH6, PMS2, MUTYH and NTHL1. From a consecutive series of 2,371 Chinese CRC patients, 140 familial and non-familial cases were selected that were diagnosed with CRC at or below the age of 35 years. Through MIP-based sequencing we identified pathogenic variants in six genes in 16 out of the $140(11.4 \%)$ patients selected. In 10 patients, known pathogenic mutations in APC (five patients), MLH1 (three patients), or MSH2 (two patients) were identified. Three additional patients were found to carry novel, likely pathogenic truncating $(n=2)$ and missense $(n=1)$ mutations in the MSH2 gene and a concomitant loss of expression of both the MSH2 and MSH6 proteins in their respective tumor tissues. From our data, we conclude that targeted MIP-based sequencing is a reliable and cost-efficient approach to identify patients with a Mendelian CRC syndrome.

\section{INTRODUCTION}

Colorectal cancer (CRC; MIM 114500) is the third most common cancer in males and the second in females worldwide, with 1.2 million patients diagnosed annually [1]. In China, CRC is the fifth most commonly diagnosed cancer and the fifth leading cause of cancer-related death among both men and women, with an estimated 376,300 new patients and 191,000 deaths in 2015. Moreover, the age-standardized CRC incidence and mortality rates in China have shown a clear upward trend in recent years [2]. A family history of CRC or an early age at diagnosis are 
indications for a genetic predisposition. Genetic factors are estimated to account for the development of $\sim 30 \%$ of all CRCs [3]. The currently known Mendelian CRC predisposition syndromes, caused by germline mutations in single predisposing genes, account for $\sim 5-10 \%$ of all CRCs [4]. Examples of autosomal dominant Mendelian CRC syndromes are Lynch syndrome (LS) caused by mutations in the mismatch repair (MMR) genes $M L H 1$, MSH2, MSH6 or PMS2, familial adenomatous polyposis (FAP) caused by mutations in the $A P C$ gene and polymerase proofreading-associated polyposis (PPAP) caused by mutations in the exonuclease domain of the POLE or POLD1 genes. Thus far, two autosomal recessive Mendelian CRC syndromes have been described, namely MUTYH-associated polyposis (MAP) caused by biallelic mutations in the MUTYH gene and NTHL1-associated polyposis caused by biallelic mutations in the NTHL1 gene [4-7]. A timely identification of individuals at a high risk to develop CRC allows presymptomatic screening and genetic counseling, which may lead to reductions in both morbidity and mortality [8,9].

In Western countries, CRC patients that are suspected of having a genetic predisposition for CRC are usually referred for genetic counseling to a clinical geneticist, who may advice for genetic testing. Until recently this testing was performed on a gene-by-gene basis, starting with the most likely candidate gene. With the advent of next-generation sequencing (NGS) technologies, however, it has become realistic to test a large panel of genes in a single assay, which is less laborious, less costly and less time-consuming [10]. Such an approach is also within reach now for centers and hospitals in which testing for a genetic cancer risk is not performed on a routine basis, as is the case in China.

Here, we describe a targeted next-generation sequencing panel of molecular inversion probes (MIPs) to identify high-penetrance CRC predisposing mutations in early-onset or familial CRC patients from China. We designed customized MIPs for the coding regions of seven high-penetrance CRC susceptibility genes, i.e., $A P C$, MLH1, MSH2, MSH6, PMS2, MUTYH and NTHL1 (POLE and $P O L D 1$ exonuclease domains were independently tested by Sanger sequencing), and evaluated the performance of these MIPs in the detection of genetically predisposed patients diagnosed before the age of 35 .

\section{RESULTS}

\section{Patient cohort characteristics}

An unselected series of 2,371 CRC patients aged between 15 and 93 years (median age 59 years old) was collected (Figure 1). The majority of these patients was aged 48-73 years. From this series, patients diagnosed at or before the age of 35 years (early-onset) were selected for the current study, i.e., 140 cases of which 84 (60\%) were male (Figure 1). The median age of onset was 31 years [range 15-35 years]. The demographic and clinical features of this cohort of 140 cases are listed in Table 1.

\section{Performance of the MIP sequencing panel}

The MIP sequencing panel was designed to cover all coding exons and intron-exon boundaries (+/-20 bp) of seven selected CRC predisposing genes with double tiling. Sequence capture and library preparation was performed for all 140 samples, using unique barcodes per sample. After sequencing, $99.0 \%$ of the targeted regions of interest (ROIs) were covered at least 10-fold. The mean read depth was 4,055x [range 50x-15,770x] for $A P C, M L H 1, M S H 2$, MSH6, PMS2 and MUTYH ('six-gene' panel) and 1,086x [range $63 \mathrm{x}-3,895 \mathrm{x}$ ] for NTHL1. On average, $97.8 \%$ and $83.3 \%$ of the ROIs were covered $>100 \mathrm{x}$ for the six-gene panel and for NTHL1, respectively (Figure 2). Three ROIs were not covered or had an average coverage of $<100 \mathrm{x}$, i.e., exon 2 of $A P C$ (no reads), exon 1 of MSH6 (average coverage $92 \mathrm{x}$ ) and exon 5 of NTHL1 (average coverage 63x) (Figure 2).

\section{Identification of pathogenic germline variants in early-onset $\mathrm{CRC}$ cases}

After a stringent filtering procedure (summarized in Figure 3), 30 candidate pathogenic variants were selected for further analysis. Of these 30 candidate variants, 17 were confirmed by Sanger sequencing, whereas the other 13 with either a low sequencing depth $(<300 x)$ or a low percentage of variant reads $(<20 \%)$ appeared to be false-positives (Supplementary Table 1). Among the 17 validated pathogenic variants (Figure 4), 13 were previously reported in the LOVD or ClinVar databases as pathogenic mutations underlying the respective hereditary CRC syndromes (Table 2). Five germline mutations were identified in the $A P C$ gene, including one nonsense mutation (c.694C $>$ T, p.Arg232Ter) and four frameshift mutations (c.3202_3205delTCAA, p.Ser1068Glyfs*57 $(n=2)$, c.3807_3808delAT, p.Ile1269Metfs*6 and c.3885delA, p.Ala1296Glnfs*9). Two probands carried a monoallelic splice site mutation (c.934-2A>G, p.Glu313Serfs*8) in the MUTYH gene, which was previously reported as potentially pathogenic in Japanese and Korean CRC patients [11, 12]. In addition, we found two known nonsense (c.676C $>\mathrm{T}$, p.Arg226Ter and c.887T $>$ G, p.Leu296Ter) and two pathogenic missense (c.793C $>$ T, p.Arg265Cys and c. $1742 \mathrm{C}>\mathrm{T}$, p.Pro581Leu) mutations in the $M L H 1$ gene, and a frameshift mutation (c.1457_1460delATGA, p.Asn486Thrfs*10) in the MSH2 gene in two probands (Table 2). The remaining four variants, detected in the MSH2 $(n=3)$ and MSH6 $(n=1)$ genes, were not found to be present in the dbSNP, ESP and ExAC databases and were, therefore, subjected to further analysis (see below). No pathogenic mutations were identified in the NTHL1 gene, and none of the genes was affected by germline copy number alterations using the CoNVaDING (Copy Number Variation Detection In Next-generation sequencing Gene panels) tool [13]. 
Table 1: Demographic and clinical characteristics of the study subjects

\begin{tabular}{|c|c|c|}
\hline Characteristic & CRC diagnosed at $\leq 35$ years & CRC diagnosed at $>35$ years \\
\hline Total patients & $140(5.9)$ & $2,231(94.1)$ \\
\hline \multicolumn{3}{|l|}{ Age } \\
\hline Median age of onset (range) & $31(15-35)$ & $60(36-93)$ \\
\hline Mean age of onset & 29.9 & 60.1 \\
\hline \multicolumn{3}{|l|}{ Gender } \\
\hline Male $(\%)$ & $84(60.0)$ & $1,312(61.6)$ \\
\hline Female $(\%)$ & $56(40.0)$ & $819(38.4)$ \\
\hline \multicolumn{3}{|l|}{ Diagnosis } \\
\hline Colon adenoma $(\%)^{1}$ & $8(5.7)$ & $33(1.5)$ \\
\hline Colon cancer $(\%)^{2}$ & $65(46.4)$ & $1,005(45.1)$ \\
\hline Rectal adenoma $(\%)^{1}$ & $2(1.4)$ & $14(0.6)$ \\
\hline Rectal cancer $(\%)^{2}$ & $65(46.4)$ & $1,179(52.8)$ \\
\hline
\end{tabular}

${ }^{1}$ At least three adenomas detected; ${ }^{2}$ In the absence of (multiple) adenomas.

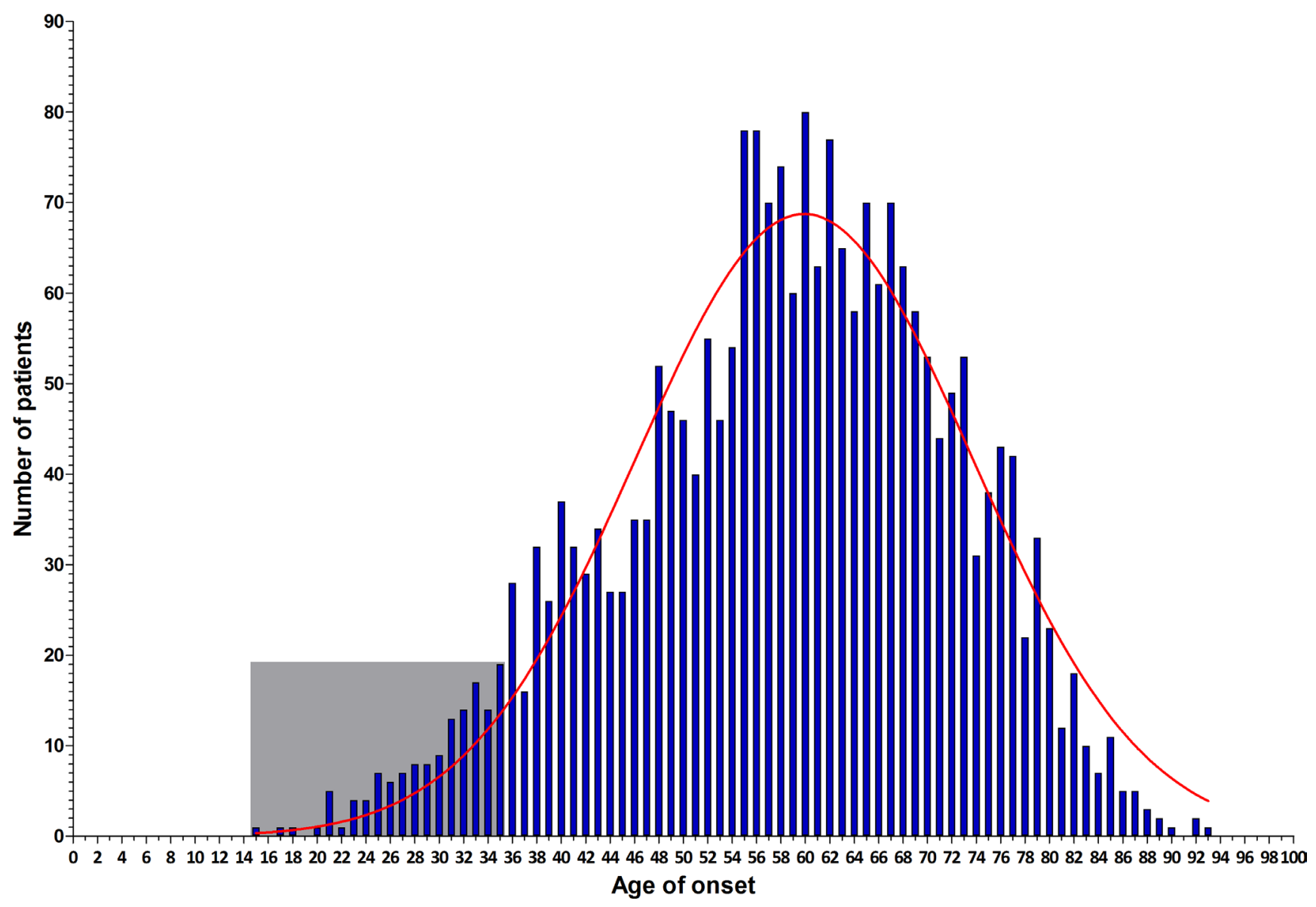

Figure 1: Age distribution histogram of the entire CRC patients series $(\boldsymbol{n}=\mathbf{2 , 3 7 1})$. The frequency distribution per year-of-age in the entire CRC patient cohort is illustrated by blue bars, which show a normal distribution (red curve). The early-onset CRC patients enrolled for MIP-based sequencing are shown in the light gray square. 


\section{Characterization of novel germline variants in early-onset CRC cases}

Two novel truncating mutations and one novel missense mutation in the MSH2 gene (c.1062 1066delCAGAA, p.Ile356Glyfs*31, c.2557G >T, p.Glu853Ter and c.2039G $>$ A, p.Arg680Gln) were identified in patients 13B-ON2505BD1 (male, rectal cancer at the age of 32 years), 13B-ON2469BD1 (male, sigmoid colon cancer at the age of 31 years) and B1287 (female, rectal cancer at the age of 30 years), respectively. One novel missense mutation in the MSH6 gene (c.3955A>C, p.Lys1319Gln) was identified in patient 14B-ON3654BD1 (female, rectal cancer at the age of 34 years). Both missense variants were predicted to be pathogenic by the SIFT, Polyphen 2 and CADD algorithms (Table 3).

To assess whether the four novel MMR gene variants were indeed pathogenic, we performed immunohistochemistry (IHC) on the respective tumor tissues using antibodies directed against the MLH1, PMS2, MSH2 and MSH6 proteins. This analysis is based on the notion that a somatic second-hit mutation in the wild-type allele will result in loss of MLH1 and PMS2 expression in MLH1-mutated cases, loss of both MSH2 and MSH6 expression in MSH2-mutated cases and loss of MSH6 expression in MSH6-mutated cases [14, 15]. Formalin fixed paraffin embedded (FFPE) tissue blocks of seven cases were available for verification by IHC, including the four cases with novel mutations in the $\mathrm{MSH} 2$ or MSH6 genes. In the tumors derived from patients B838 and B1366, immunostaining was performed only for the MLH1 and MSH2 proteins. The remaining five patients' tumor tissues were stained for all four MMR proteins (MLH1, MSH2, MSH6 and PMS2). Patients B838, B1366 and 14B-ON3619BD1, who carried known pathogenic variants in the $M L H 1$ gene, concordantly showed absence
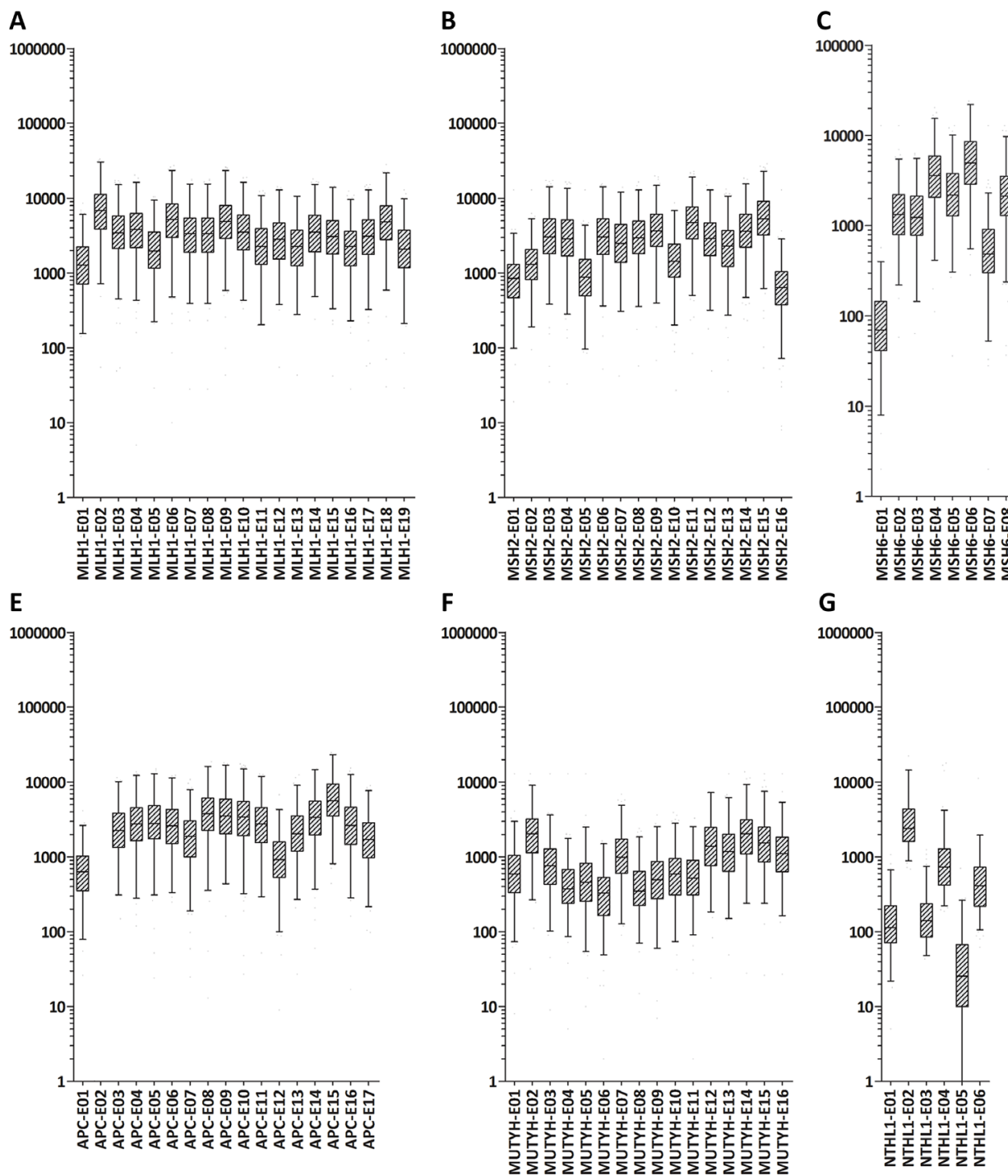

Figure 2: Mean read depth for each of the 99 exons targeted in the MIP panels. Box plots of mean read depth of the targeted exons with boxes representing $\pm 25 \%$ and whiskers depicting the $5-95 \%$ percentiles (Y-axis: fold coverage, x-axis: exons included for targeted sequencing). Mean read depth per exon of MLH1 (A), MSH2 (B), MSH6 (C), PMS2 (D), APC (E), MUTYH (F), and NTHL1 (G). 
of MLH1 nuclear staining in their tumors. The tumor tissue from patient 14B-ON3619BD1 also showed a negative IHC staining for PMS2 (Table 4, Supplementary Figure 1). The three cases with novel mutations in the MSH2 gene (13B-ON2505BD1, B1287 and 13B-ON2469BD1) all showed loss of expression of both the MSH2 and MSH6 proteins in their tumor tissues, which strongly suggests that these variants are indeed pathogenic. In patient 14B-ON3654BD1, carrying a novel missense variant in the MSH6 gene, a normal expression of all MMR proteins was observed in the tumor tissue, indicating that this mutation may not be pathogenic (Table 4, Figure 5).

\section{Contribution of known and novel germline pathogenic mutations}

Taken together, we identified pathogenic or likely pathogenic germline mutations in 16 of the 140 patients tested, and firmly established a diagnosis in 14 patients (10\%) (Figure 6). The most frequently diagnosed syndrome was Lynch Syndrome (9 cases; 6.4\%). Four patients $(2.9 \%)$ carried a mutation in the $M L H 1$ gene and five patients $(3.6 \%)$ carried a mutation in the $M S H 2$ gene. FAP, caused by mutations in $A P C$, was diagnosed in $3.6 \%$ ( 5 cases) of the patients. Two patients carried a monoallelic mutation in the MUTYH gene, but mutations in the remaining allele, which would be indicative for the diagnosis of MAP, were not detected.

\section{DISCUSSION}

A targeted next-generation sequencing panel using molecular inversion probes (MIPs) was developed to identify high-penetrance mutations in the CRC predisposing genes $A P C, M L H 1, M S H 2$, MSH6, PMS2, MUTYH and NTHL1. We applied this panel to a cohort of 140 early-onset Chinese CRC patients (diagnosed at or below the age of 35 years). Using this approach, we identified known pathogenic mutations in 13 cases, and in three additional cases novel, likely pathogenic,

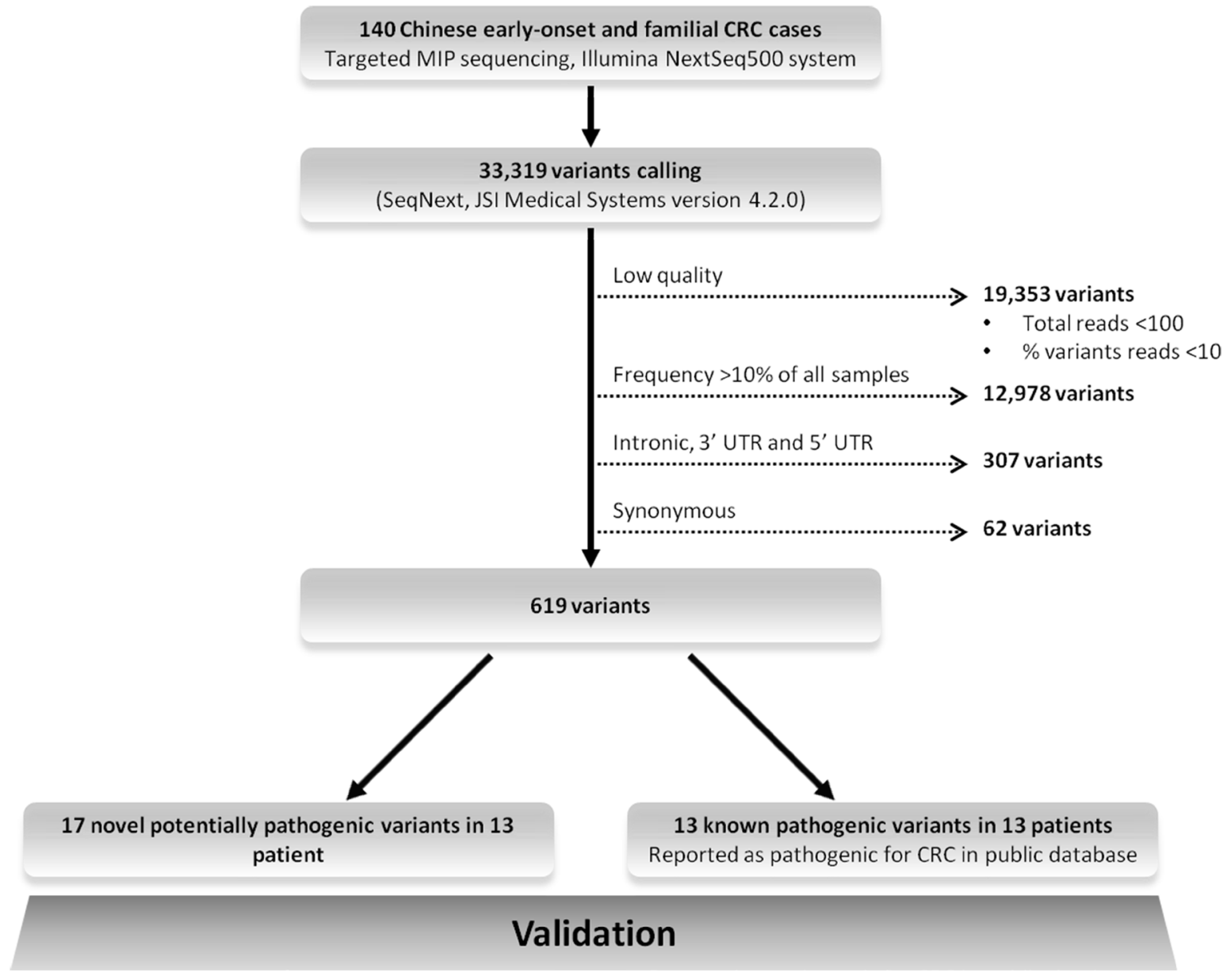

Figure 3: Schematic chart showing the stepwise strategy for the detection of pathogenic mutations. Dashed arrows represent exclusion criteria. Germline variants known to be associated with hereditary CRC syndromes were initially selected and searched for evidence of pathogenicity in relevant databases, i.e., InSiGHT (http://www.insight-group.org/), LOVD (https://atlas.cmm.ki.se/ LOVDv.2.0/), the Mismatch Repair Genes Variant Database (http://www.med.mun.ca/mmrvariants/) and Clinvar (http://www.ncbi.nlm. nih.gov/clinvar/). Next to the identification of known pathogenic variants, we searched for novel potential pathogenic rare variants (For details see Materials and Methods section). 
Table 2: Known germline pathogenic variants in CRC predisposing genes for early-onset CRC

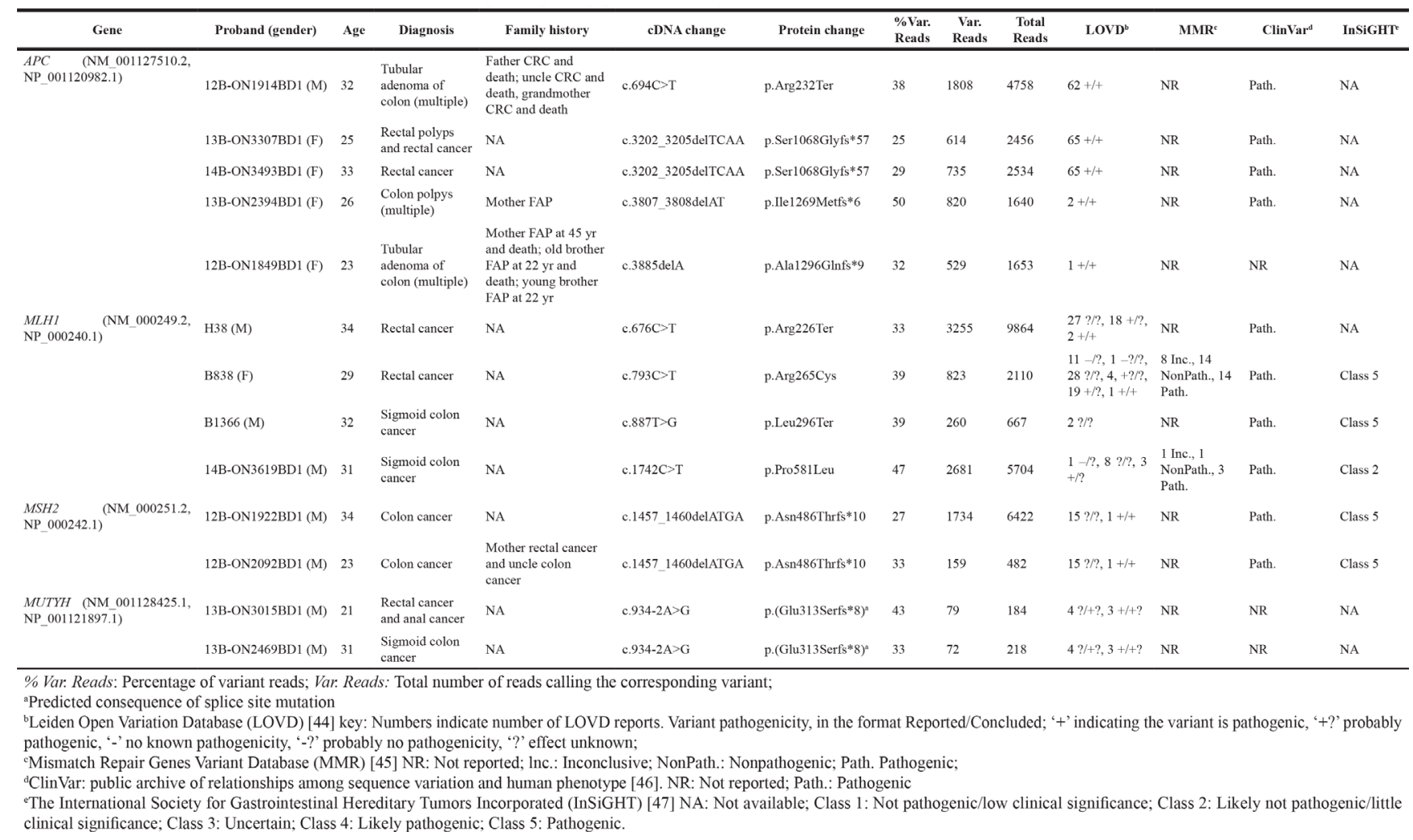

Table 3: Novel germline variants in known CRC predisposing genes

\begin{tabular}{|c|c|c|c|c|c|c|c|c|c|c|c|c|c|}
\hline Gene & Proband (gender) & Age & Diagnosis & $\begin{array}{l}\text { Family } \\
\text { history }\end{array}$ & cDNA change & Protein change & $\begin{array}{l}\text { \%Var. } \\
\text { Reads }\end{array}$ & $\begin{array}{l}\text { Var. } \\
\text { Reads }\end{array}$ & $\begin{array}{l}\text { Total } \\
\text { Reads }\end{array}$ & phyloP & SIFT & PolyPhen2 & CADDa \\
\hline \multirow[t]{3}{*}{$\begin{array}{l}\text { MSH2 (NM_000251.2, } \\
\text { NP_000242.1) }\end{array}$} & $\begin{array}{l}\text { 13B-ON2505BD1 } \\
\text { (M) }\end{array}$ & 32 & Rectal cancer & NA & c.1062_1066delCAGAA & p.Ile356Glyfs*31 & 18 & 599 & 3328 & & & & 35 \\
\hline & $\begin{array}{l}\text { 13B-ON2469BD1 } \\
\text { (M) }\end{array}$ & 31 & $\begin{array}{l}\text { Sigmoid colon } \\
\text { cancer }\end{array}$ & NA & c. $2557 \mathrm{G}>\mathrm{T}$ & p.Glu853Ter & 16 & 369 & 2306 & & & & 40 \\
\hline & B1287 (F) & 30 & Rectal cancer & NA & c. $2039 \mathrm{G}>\mathrm{A}$ & p.Arg680Gln & 15 & 309 & 2060 & 6.34 & Del & PRD & 35 \\
\hline $\begin{array}{l}\text { MSH6 (NM_000179.2, } \\
\text { NP } 000170.1)\end{array}$ & 14B-ON3654BD1 (F) & 34 & Rectal cancer & NA & c. $3955 \mathrm{~A}>\mathrm{C}$ & p.Lys1319Gln & 39 & 260 & 667 & 5.21 & Del & POD & 23.2 \\
\hline
\end{tabular}

M: male; F: female; \% Var. Reads: Percentage of variant reads; Var. Reads: Total number of reads calling the corresponding variant; Del: Deleterious; PRD: PROBALY DAMAGING; POD: POSSIBLY DAMAGING; $\boldsymbol{D C}$ : Disease causing

${ }^{a}$ Combined Annotation Dependent Depletion (CADD) [40]. Here we apply a cutoff $(\mathrm{C}$ score $=15)$ on deleteriousness.

mutations in the $\mathrm{MSH} 2$ gene were found with confirmed loss of MSH2 protein expression in the tumors. Two of the 13 patients were found to carry a known pathogenic monoallelic MUTYH mutation, of which the clinical relevance remains inconclusive at this point. Therefore, a firm diagnosis could be made in 14 cases $(10 \%)$.

The diagnosis hereditary CRC mainly relies on clinico-pathological features, family history and genetic data. Although international criteria for hereditary CRC have been defined, such as the Amsterdam criteria I and II, the Bethesda guidelines and the Japanese standards, they are not suitable for small pedigrees, which are common in China. Furthermore, the characteristics of hereditary CRC cases in the Chinese population may differ from those in Western countries [16]. As of yet, genetic testing for hereditary CRC is not performed on a routine basis in China. The recent development and implementation of next-generation sequencing technologies makes rapid and cost-effective genome sequencing feasible. Particularly, targeted sequencing approaches are highly suitable for implementation in routine diagnostic testing of patients with a suspected (colorectal) cancer syndrome. Here, we used MIP-based sequencing, a recently developed approach that has successfully been applied to targeted DNA sequencing of clinical samples [17, 18]. MIPs provide a high target sensitivity (99\%) and specificity $(98 \%)$ at low costs and minimal DNA requirements, and can be easily multiplexed to target regions of multiple genes in a single reaction [18]. Implementation of this methodology in routine diagnostics requires further adjustments to guarantee minimal costs and optimal turnaround times, which are highly dependent on sample supply, available infrastructure, and local personnel costs $[19,20]$. For a MIP-based breast cancer susceptibility gene panel, a turnaround time of 4 days has been described [19]. Therefore, we consider MIP-based sequencing as a highly suitable replacement of Sanger sequencing for clinical genetic testing [17]. 
Table 4: Immunohistochemical expression of DNA MMR proteins in tumor tissue of patients carrying MMR gene mutations

\begin{tabular}{|c|c|c|c|c|c|c|c|}
\hline \multirow{2}{*}{ Gene } & \multirow{2}{*}{ Proband } & \multirow{2}{*}{ Gene } & \multirow{2}{*}{ Protein change } & \multicolumn{4}{|c|}{ Tumor expression of MMR proteins } \\
\hline & & & & MLH1 & PMS2 & MSH2 & MSH6 \\
\hline \multirow{6}{*}{$\begin{array}{l}\text { Known germline pathogenic } \\
\text { mutations }\end{array}$} & H38 & MLH1 & p.Arg226Ter & N/A & N/A & $\mathrm{N} / \mathrm{A}$ & N/A \\
\hline & B838 & $M L H 1$ & p.Arg265Cys & - & N/A & + & N/A \\
\hline & B1366 & MLH1 & p.Leu296Ter & - & N/A & + & N/A \\
\hline & 14B-ON3619BD1 & $M L H 1$ & p.Pro581Leu & - & - & + & + \\
\hline & 12B-ON1922BD1 & MSH2 & p.Asn486Thrfs*10 & N/A & N/A & $\mathrm{N} / \mathrm{A}$ & N/A \\
\hline & 12B-ON2092BD1 & MSH2 & p.Asn486Thrfs*10 & N/A & N/A & N/A & N/A \\
\hline \multirow{4}{*}{$\begin{array}{l}\text { Rare and novel germline } \\
\text { pathogenic mutations }\end{array}$} & 13B-ON2505BD1 & MSH2 & p.Ile356Glyfs*31 & + & + & - & - \\
\hline & B1287 & MSH2 & p.Arg680Gln & + & + & - & - \\
\hline & 13B-ON2469BD1 & MSH2 & p.Glu853Ter & + & + & - & - \\
\hline & 14B-ON3654BD1 & MSH6 & p.Lys1319Gln & + & + & + & + \\
\hline
\end{tabular}

N/A: Not available.

We found that with our newly designed MIP sequencing panel $99 \%$ of the target regions of interest (ROIs) were covered at least 10x. The majority $(97 \%$, 96/99) of the target ROIs was covered more than 100x (ranging from 186x to 15,770x), whereas exon 2 of $A P C$, exon 5 of NTHL1 and exons 1 of MSH6 showed poor coverages. For $A P C$, no pathogenic or likely pathogenic mutations in exon 2 associated with CRC or FAP have been reported in the LOVD [21]. Exon 5 of NTHL1 showed a mean coverage of $63 \mathrm{x}$ and exon 1 of MSH6 showed a mean coverage of $92 x$. Further probe rebalancing and supplementation may improve the capture uniformity from probe to probe and the coverage of the poorly captured regions. For the candidate pathogenic variants, Sanger sequencing-based validation revealed that 17 variants with a good coverage $(>600 \mathrm{x})$ and a high mutant allele frequency $(\geq 25 \%$ ) could readily be confirmed, while the other 13 discrepant variants with a relatively low sequencing depth $(<300 x)$ or a low variant allele frequency $(<20 \%)$ could not be confirmed (Supplementary Table 1), suggesting that further optimization of the thresholds for read depth and variant allele frequency will lower the number of false positives. The use of a higher thresholds for variant calling may decrease the chance to detect patients with (rarely occurring) germline mutations that are present in a low-mosaic state [22]. To overcome this limitation, we recently applied single-molecule molecular inversion probes (smMIPs) to FFPE tissue-derived DNA, which performs molecular tagging of DNA molecules, and gives reliable results [20].

Of note, among the 17 confirmed mutations identified, $13(76.5 \%)$ were previously reported to be associated with hereditary CRC syndromes in public databases such as InSiGHT, LOVD and the Mismatch
Repair Genes Variant database. Three novel mutations in the $M S H 2$ gene were considered to be likely pathogenic, whereas one novel missense variant in the MSH6 gene may not be pathogenic based on our IHC staining results. Together, these pathogenic and likely pathogenic germline mutations explain $10 \%$ of the early-onset CRC patients included in our cohort. Some of the remaining $90 \%$ of the patients in our cohort may carry germline mutations in known genes that are not included in our panel yet, such as SMAD4/BMPR1A, POLE or POLD1, or in genes that still await discovery. However, it is likely that the majority of these cases does not carry a mutation in a highpenetrant gene. Lower penetrance genetic factors and/or environmental factors may have caused the early onset of colorectal cancer in these cases, as has recently been proposed [23].

With five pathogenic germline mutations in five patients, $A P C$ is the most frequently mutated CRC predisposition gene in our cohort. Indeed, from four of these patients a polyposis phenotype $(>100$ colonic polyps) had indeed been recorded. With mutations detected in 6 MMR genes, Lynch Syndrome is the most prevalent CRC syndrome encountered in our cohort, which is in agreement with a previous study using whole exome sequencing of Chinese early-onset and familial CRC patients [24] and with the studies of Tanskanen et al. [25] and Chubb et al. [23]. Others have reported various frequencies of germline MMR gene mutations in selected CRC cohorts with a broad range in estimates of their contributions to CRC development [26]. $M S H 2$ was found to be the most frequently mutated MMR gene in our cohort, which is consistent with other studies in southern Chinese CRC patients reported by Liu et al. [27], Yang et al. [28] and Jin et al. [29]. However, this frequency differs 
A

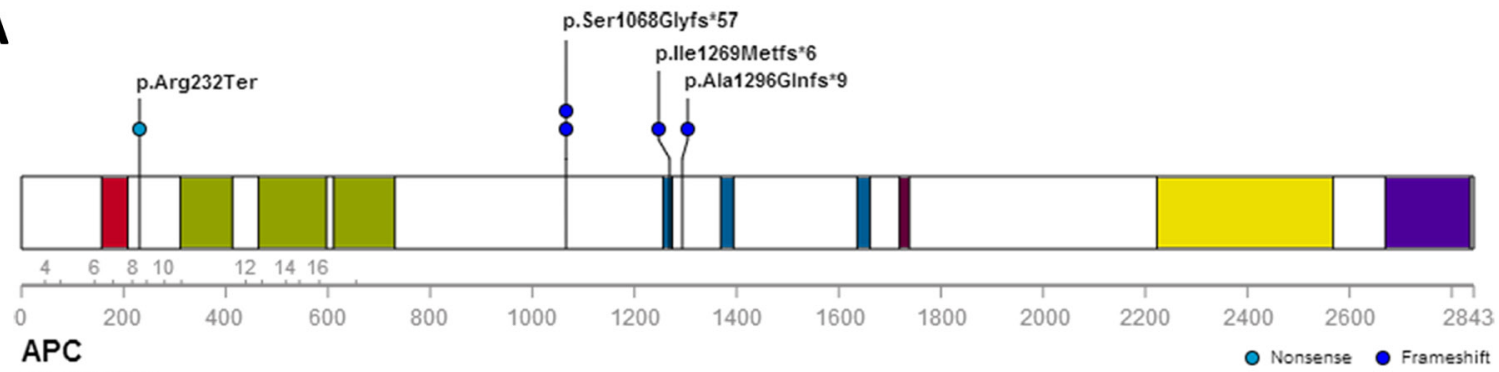

NM_001127510

$\square$ ARM - Armsdillo/bets-catenin-like repests

SAMP - SAMP Motif $\quad \square$ APC_bssic-APC basio domsin

B

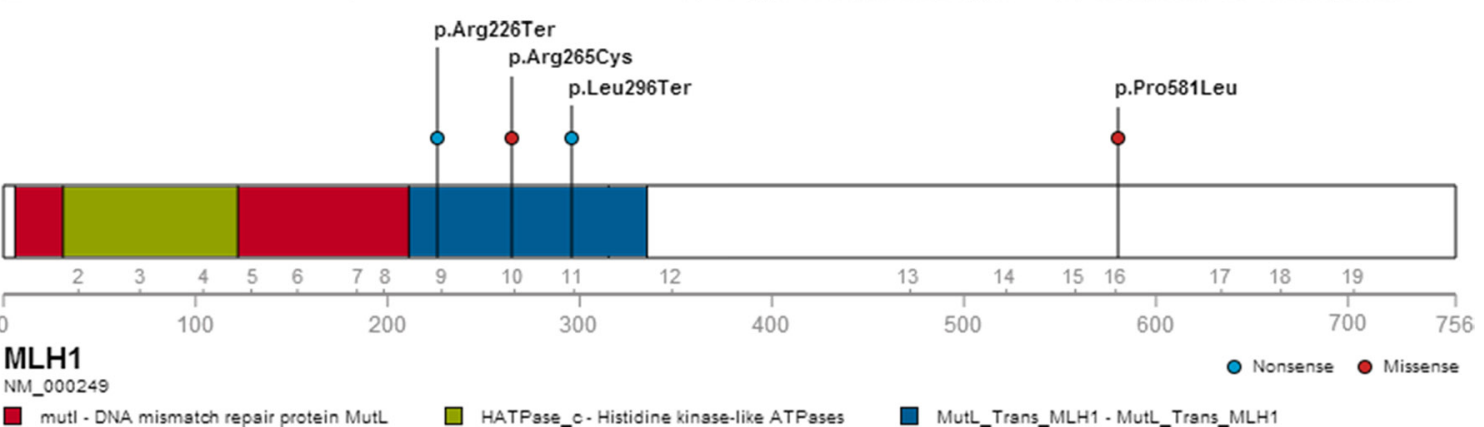

C

mutl - DNA mismatch repgir protein MutL

$\square$ HATPgse_0. Histidine kingse-like ATPases

MutL_Trans_MLH1 - MutL_Trans_MLH1

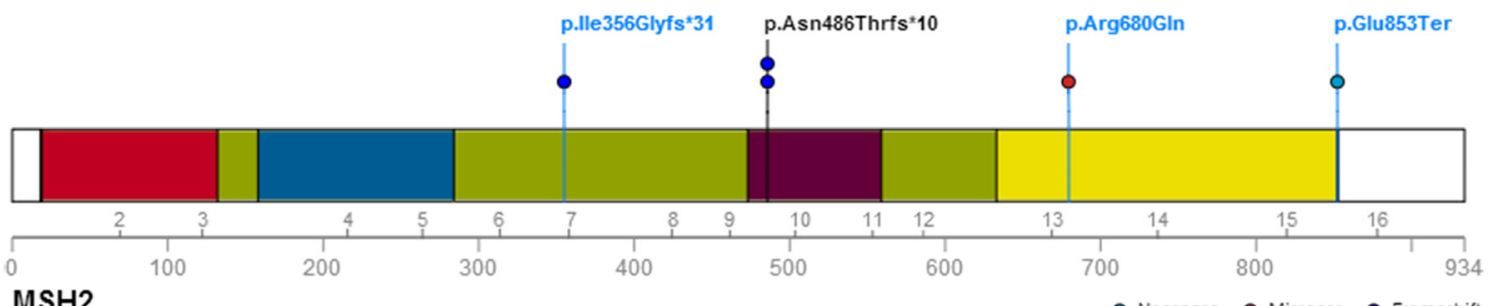

$\mathrm{MSH} 2$

NM_000251

$\square$ Muts_l-Muts domain I

MutS_IV - MutS family domain IV

- Nonsense

Missense Frameshift

$\square$ Muts - Mismatch repgir ATPase (MutS family)

$\square$ ABC_MSH2_euk - MutS2 homolog in eukgryotes

D

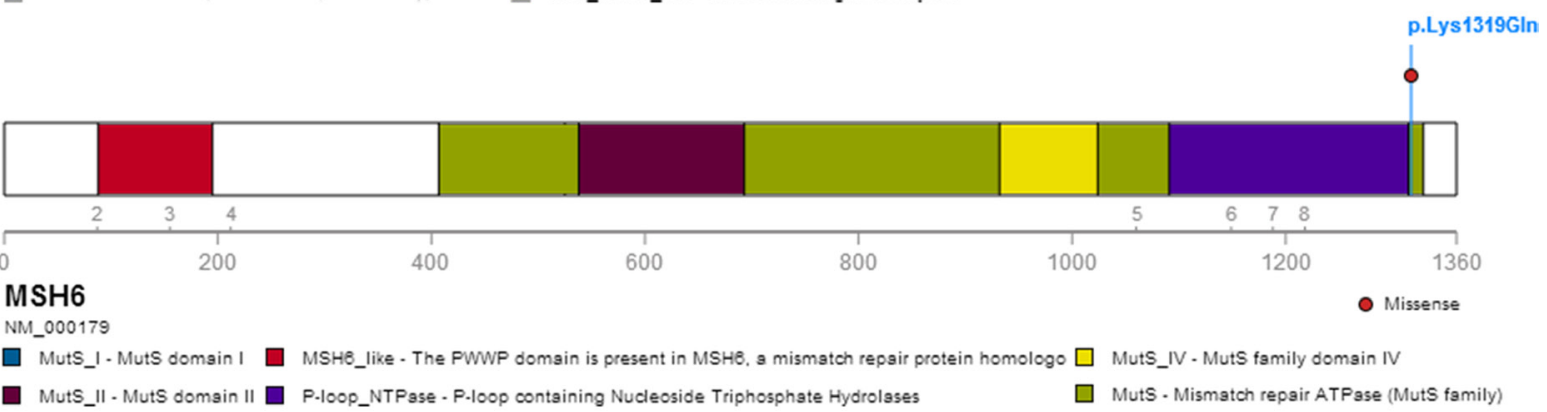

E

MutS_II - MutS domain II $\square$ P.100p_NTPase · P.loop containing Nucleoside Triphosphate Hydrolases

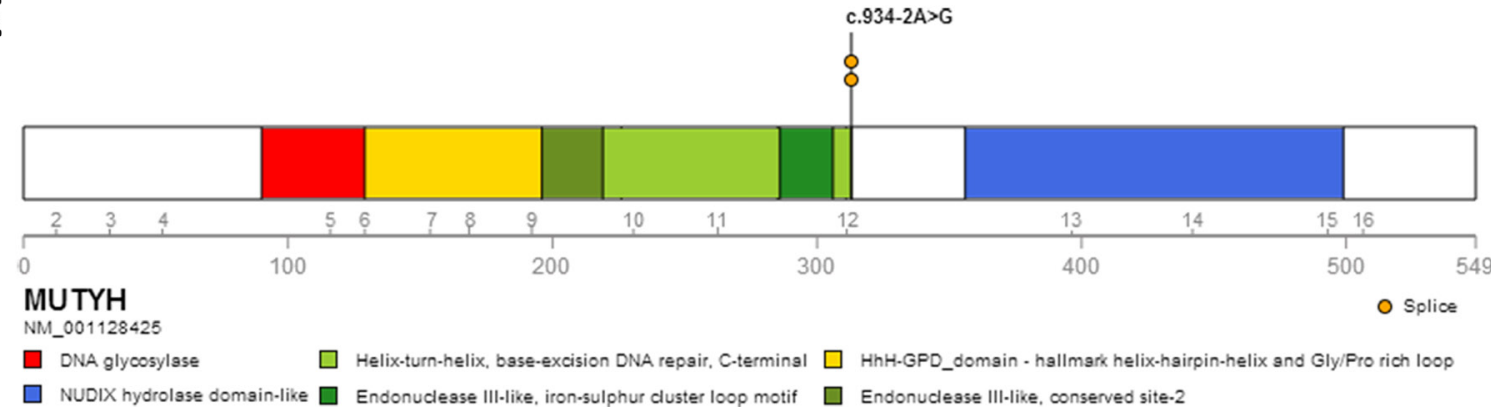

Figure 4: Protein alterations resulting from the mutations in known CRC predisposing genes identified in the studied cohort. The alterations are shown for $A P C(\mathbf{A}), M L H 1$ (B), MSH2 (C), MSH6 (D) and MUTYH (E). Alterations shown in blue represent newly identified pathogenic mutations in this study; black entries denote previously reported pathogenic mutations in hereditary CRC syndromes. No loss of MSH6 protein expression was observed in the tumor of patient 14B-ON3654BD1, carrying the MSH6 missense variant p.Lys1319Gln. 


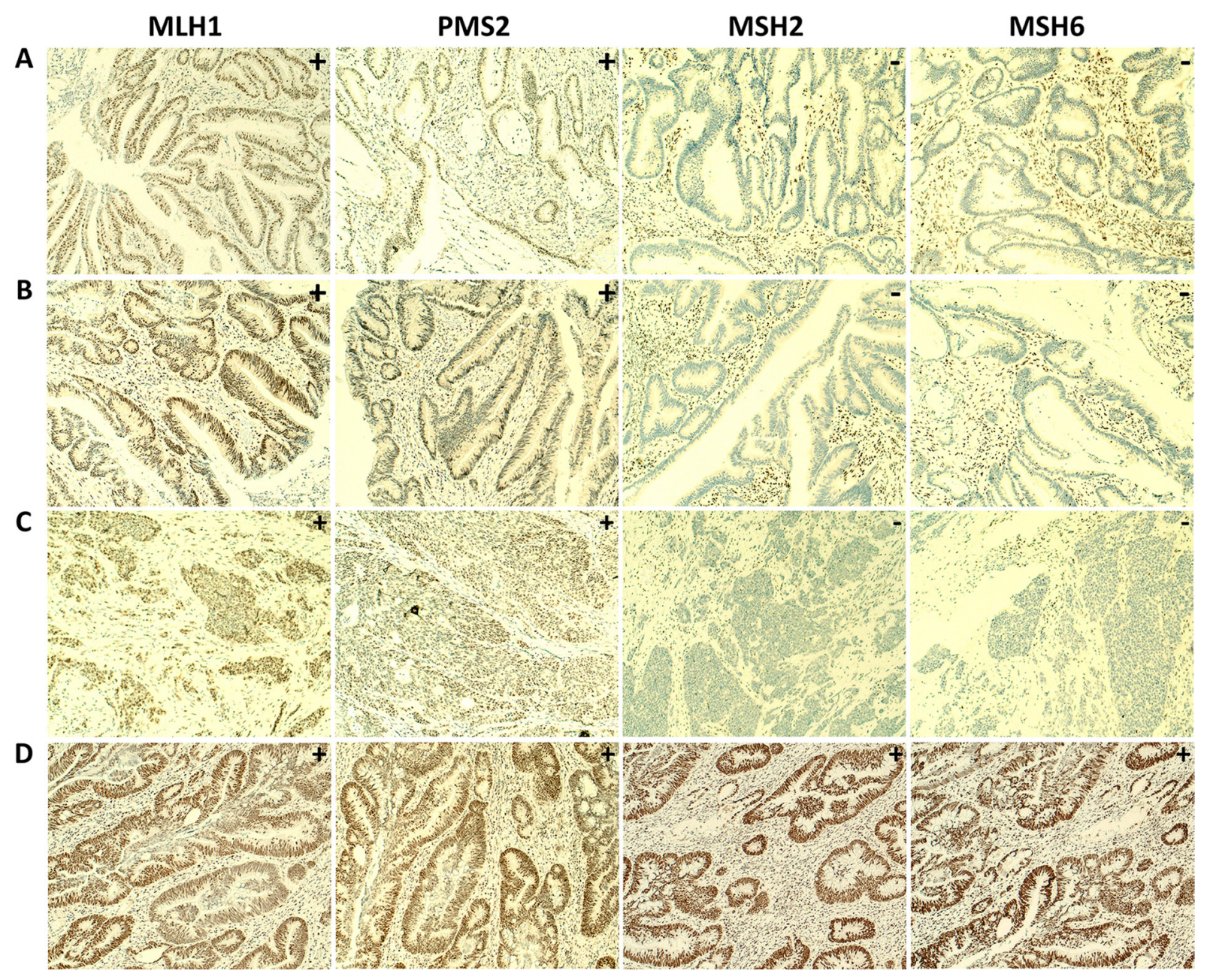

Figure 5: IHC staining of MMR proteins in tumor tissue of four patients carrying rare and novel germline mutations. Loss of nuclear expression of the MSH2 and MSH6 proteins and normal expression of the MLH1 and PMS2 proteins in tumor tissues were observed in (A) patient 13B-ON2505BD1, with the MSH2 p.Ile356Glyfs*31 frameshift mutation, (B) patient B1287, with the MSH2 missense mutation p.Arg680Gln and (C) patient 13B-ON2469BD1, with the MSH2 nonsense mutation p.Glu853Ter. Normal staining of the MLH1, PMS2, MSH2 and MSH6 proteins was observed in (D) tumor tissue of patient 14B-ON3654BD1, with the MSH6 missense mutation p.Lys1319Gln. (100x magnification).

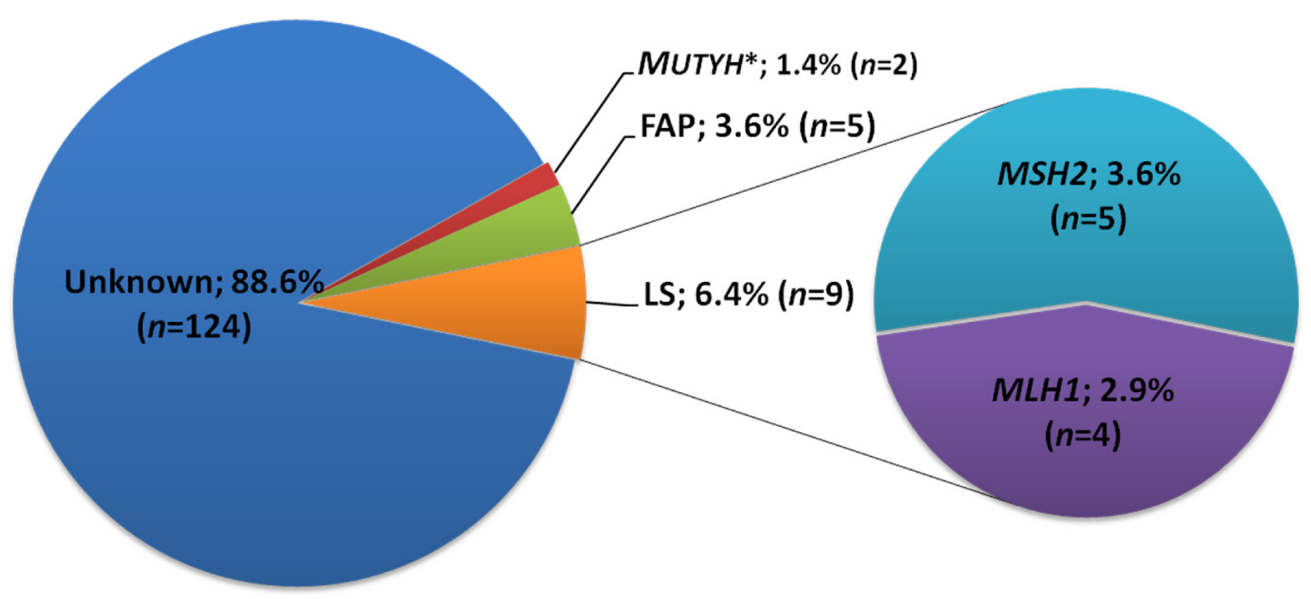

Figure 6: Contribution of known and novel germline pathogenic mutations to early-onset colorectal cancer in Chinese patients. *In both MUTYH mutated patients (13B-ON3015BD1 and 13B-ON2469BD1, unrelated) only monoallelic mutations (c.934$2 \mathrm{~A}>\mathrm{G}$; p.Glu313Serfs X8) were detected; FAP: familial adenomatous polyposis; LS: lynch syndrome. 
from other studies reporting that the $M L H 1$ gene was more frequently affected than the $\mathrm{MSH} 2$ gene [24, 30-32]. More studies are, however, required to exactly determine the $M L H 1$ and $M S H 2$ mutation rates in different regions and ethnicities in China.

We identified in two unrelated patients a monoallelic MUTYH splice site variant (c.934-2A>G, p. Glu313Serfs X8), which has been reported to be probably pathogenic in Japanese and Korean CRC patients [11, 12]. Although no mutations were identified on the second MUTYH allele in these two individuals, it is still possible that pathogenic germline mutations are present on this allele outside the detection range of our MIP sequencing panel (i.e., introns or promoter). Sequencing of tumorderived DNA of these patients may additionally reveal whether the somatic mutations present are biased towards $\mathrm{G}>\mathrm{A}$ transversions, which is a typical feature of MAPassociated tumors [33].

In summary, we developed a MIP-based nextgeneration sequencing panel that targets the coding exons and flanking exon-intron boundaries $(+/-20 \mathrm{bp})$ of seven high-penetrant CRC predisposing genes. Our data indicate that targeted MIP-based sequencing is a reliable approach for the identification of Chinese early-onset CRC patients with a Mendelian syndrome. This approach is cost- and time-efficient compared to Sanger sequencing [18]. For the specific purpose of molecular diagnostics, this strategy shows advantages over phenotype-based gene-specific testing. Since the international standards on hereditary CRC are not applicable to small families as commonly seen in China, such a sequencing-based strategy may be particularly beneficial for the Chinese population.

\section{MATERIALS AND METHODS}

\section{Study subjects}

Whole blood from 2,391 patients with CRC was collected between 2007 and 2014 by the Sixth Affiliated Hospital, Sun Yat-sen University, Guangzhou, China. Probands with an age at diagnosis of $\leq 35$ years, with or without a family history for CRC, were selected. For the current study 140 early-onsets CRC cases were included of whom DNA was available for testing. All included patients provided informed consent. This study was reviewed and approved by the Institutional Review Board of the Sixth Affiliated Hospital, Sun Yat-sen University, Guangzhou, China.

\section{Genomic DNA isolation}

Genomic DNA was extracted from peripheral blood cells using a Gentra Puregene Blood Kit (QIAGEN, Hilden, Germany) according to the protocol provided by the manufacturer. The DNA was quantified using a NanoDrop 2000 UV-Vis Spectrophotometer (Thermo
Scientific) and the DNA concentration was normalized to $25 \mathrm{ng} / \mu \mathrm{l}$ for MIP-based sequencing.

\section{Molecular inversion probe (MIP) design, capture and sequencing}

For six genes included in the targeted sequencing effort in this study, i.e., APC, MLH1, MSH2, MSH6, $P M S 2$ and MUTYH, 626 MIPs were designed. In addition, 23 MIPs targeting the last exon of EPCAM, a gene located $\sim 25 \mathrm{~kb}$ upstream of $M S H 2$, were included to allow detection of deletions of the 3' end of EPCAM, which leads to in cis inactivation of the $M S H 2$ promoter [34] (Supplementary Figure 2). For the NTHL1 gene we generated another multiplex panel of 23 MIPs (Table 5). These MIPs were designed as described previously [35], targeting the coding exons and flanking exon-intron boundaries $(+/-20 \mathrm{bp})$ of the respective genes, in total covering 22,834 of the $23,062(99.01 \%)$ coding base pairs. Except for NTHL1, all targeted regions had a double tiling. Targeted capture with MIPs was performed as previously reported [18, 36], with some slight modifications [7]. In brief, a total of $100 \mathrm{ng}$ of genomic DNA was used to capture the target regions in a mixture of $25 \mu 1$ containing 4.38E-05 picomoles 5'-phosphorylated MIPs in Ampligase DNA Ligase Buffer (Epicentre, Madison, WI, USA), 0. $32 \mu \mathrm{M}$ dNTPs (NEB, Ipswich, MA, USA), $3.2 \mathrm{U}$ Hemo Klentaq (NEB, Ipswich, MA, USA), and 1 U Ampligase $100 \mathrm{U} / \mathrm{ul}$ (Epicentre, Madison, WI, USA). After denaturation $\left(95^{\circ} \mathrm{C}\right)$ for 10 minutes and incubation $\left(60^{\circ} \mathrm{C}\right)$ for 22 hours, linear probes and the remaining genomic DNA were removed by exonuclease treatment. Next, the captured material was amplified by PCR using barcoded reverse primers. The resulting PCR products were pooled and combined (140 samples) into a library. The resulting libraries (from the two multiplex panels) were sequenced using an Illumina NextSeq500 system, with $2 \times 150$-bp paired-end reads.

\section{Data analysis and variant calling}

Barcode-specific FASTQ files were mapped and annotated for APC (NM_001127510.2), MLH1 (NM_000249.2), MSH2 (NM_000251.2), MSH6 (NM_000179.2), PMS2 (NM_000535.5), MUTYH (NM_001128425.1) and NTHL1 (NM_002528.5), and variants were called using SeqNext (JSI Medical Systems; version 4.2.0). Subsequently, we selected all variants not found in our in-house database $(5,036$ in-house analyzed exomes, without suspected cancer predisposition, mostly from European ancestry), and with a MAF $<0.001$ in dbSNPv142, Exome Variant Server, NHLBI GO Exome Sequencing Project (ESP), Seattle, WA (6,503 exomes, URL: http://evs.gs.washington.edu/EVS/) and Exome Aggregation Consortium (ExAC), Cambridge, MA (60,706 unrelated exomes, http://exac.broadinstitute.org). 
Table 5: Summary of 7 high-penetrance CRC genes in the MIP panel

\begin{tabular}{|c|c|c|c|c|c|c|c|c|c|}
\hline Gene & $\begin{array}{l}\text { Gene Acession } \\
\text { Number }\end{array}$ & $\begin{array}{c}\text { \# of } \\
\text { Exons }\end{array}$ & $\begin{array}{c}\text { \# of } \\
\text { Coding } \\
\text { Bases }\end{array}$ & $\begin{array}{c}\# \text { of } \\
\text { Targeted } \\
\text { Coding } \\
\text { Bases }\end{array}$ & $\begin{array}{l}\text { \# of } \\
\text { MIPs }\end{array}$ & $\begin{array}{l}\text { Associtated } \\
\text { Syndromes }\end{array}$ & $\begin{array}{c}\text { Associated Cancers }{ }^{\mathrm{d}} \\
\text { (Lifetime risk (\%) or fold- } \\
\text { increase in risk) }\end{array}$ & $\begin{array}{c}\text { NCCN } \\
\text { Guidelines } \\
{[48]}\end{array}$ & References \\
\hline$A P C$ & NM_001127510.2 & 17 & 8725 & 8618 & 201 & $\begin{array}{c}\text { Familial } \\
\text { Adenomatous } \\
\text { Polyposis (FAP)/ } \\
\text { Attenuated FAP } \\
\text { (AFAP) }\end{array}$ & $\begin{array}{c}\text { Colorectal }(70 \% \text { for AFAP, } \\
100 \% \text { for FAP), Duodenum/ } \\
\text { periampullary }(4-12 \%), \text { Thyroid } \\
(1-2 \%), \text { Hepatoblastoma }(1-2), \\
\text { Pancreas }(2 \%), \text { Medulloblastoma } \\
(<1 \%), \text { Gastric }(<1 \%)\end{array}$ & Y & [48-51] \\
\hline MLH1 & NM_000249.2 & 19 & 2271 & 2218 & 86 & \multirow{4}{*}{ Lynch Syndrome } & Colorectal (15-82\%), Endometrial & \multirow{4}{*}{ Y } & \multirow{4}{*}{ [52-57] } \\
\hline $\mathrm{MSH}^{\mathrm{a}}$ & NM_000251.2 & 16 & 2805 & 2750 & 112 & & $\begin{array}{c}(15-60 \%), \text { Gastric }(11-19 \%), \\
\text { Ovarian }(9-12 \%) \text {, Small intestine, }\end{array}$ & & \\
\hline MSH6 & NM_000179.2 & 10 & 4083 & 4070 & 101 & & Hepatobiliary, Upper urinary tract, & & \\
\hline PMS2 & NM_000535.5 & 15 & 2589 & 2589 & 84 & & CNS, Sebaceous gland & & \\
\hline MUTYH & NM_001128425.1 & 16 & 1650 & 1650 & 65 & $\begin{array}{l}\text { MUTYH-associated } \\
\text { Polyposis (MAP) }\end{array}$ & $\begin{array}{c}\text { Colorectal }(80 \%) \text {, Breast cancer } \\
\text { (females), Duodenum (4\%), } \\
\text { Gastric, Endometrial }\end{array}$ & Y & [58-61] \\
\hline NTHL $1^{\mathrm{b}}$ & NM_002528.5 & 6 & 939 & 939 & 23 & $\begin{array}{c}\text { NTHL1-associated } \\
\text { Polyposis }\end{array}$ & Colorectal and Endometrial & $\mathrm{N}$ & [7] \\
\hline Total & & 99 & 23062 & 22834 & 672 & & & & \\
\hline
\end{tabular}

${ }^{a}$ Targeted capture region includes coding sequence of $M S H 2$ and $25 \mathrm{~kb}$ upstream of $M S H 2$, which harbors deletion of the $3^{\prime}$ end of EPCAM leading to inactivation of the $\mathrm{MSH} 2$ promoter.

${ }^{\mathrm{b}}$ Involved in another independent panel which includes 4 DNA glycosylase genes NTHL1, OGG1, MPG and SMUG1.

c Syndromes are associated with biallelic mutations in the genes listed. With the exception of MUTYH, associated cancers specified in this table are for monoallelic mutation carriers.

${ }^{\mathrm{d}}$ Cancer risks are not yet well-defined for all cancers associated with these genes to date. If known, cancer risks are expressed by lifetime cancer risk. Gene name, number of exons, size, number of coding bases for which probes were successfully designed, and number of probes for targeted capture of the coding sequence of 7 genes harboring clinically actionable mutations.

To exclude false-positive calls due to technical artifacts, the following variant calls were excluded: less than 100fold absolute coverage, less than $10 \%$ variant reads and less than 30 variant reads. Furthermore, all unknown variants that were called in $>10 \%$ of the samples were considered as local normal variation and were also excluded.

\section{Delineation of pathogenic mutations}

A stepwise strategy was used to systematically identify putative pathogenic mutations. We initially selected germline variants known to be associated with hereditary CRC syndromes and searched for evidence of pathogenicity in relevant databases, i.e., InSiGHT (http:// www.insight-group.org/), LOVD (https://atlas.cmm. ki.se/LOVDv.2.0/), the Mismatch Repair Genes Variant Database (http://www.mmruv.info/) and ClinVar (http:// www.ncbi.nlm.nih.gov/clinvar/). Next to the identification of known pathogenic variants, we searched for novel potential pathogenic rare variants using the integrated mutation prediction software Alamut Visual version 2.5 (Interactive Biosoftware, Rouen, France). For the selection of these variants, at least one of the following criteria should be met: (i) variants that result in truncation of the protein, including nonsense and frameshift variants, and variants predicted to cause splice site defects; (ii) non-synonymous missense variants at highly conserved nucleotide positions (phyloP $\geq 3.0$ ) [37], which score "deleterious" by both SIFT [38] and PolyPhen2 [39]; (iii) variants with CADD scores $>15$ as scored by Combined Annotation-Dependent Depletion (CADD) [40], which is a method for objectively integrating diverse annotations into a single measure (C score) for each variant.

\section{Variant validation by sanger sequencing}

The identified potentially pathogenic germline variants were validated by Sanger sequencing after PCR amplification. The PCR primers were designed using the Primer3 software package [41] (primer sequences available upon request). The PCR reactions were performed using a Dual 96-Well GeneAmp PCR System 9700 (Applied Biosystems) using standard protocols. Mutation analyses were performed using the Vector NTI software package (Invitrogen, Paisley, UK).

\section{Immunohistochemical detection of MMR proteins}

Expression of the MMR proteins MLH1, MSH2, MSH6 and PMS2 was assessed by immunohistochemistry (IHC) on $4-\mu \mathrm{m}$ sections of formalin fixed paraffin embedded (FFPE) tissue samples containing tumor 
tissue and adjacent normal mucosa. IHC staining was performed using a BenchMark XT automated tissue staining system (Ventana Medical Systems, Inc., Tucson, AZ, USA), according to validated protocols provided by the manufacturer. The antibodies used were a mouse antiMLH1 monoclonal antibody (clone ES05; dilution 1:100; ZSGB-BIO), a rabbit anti-MSH2 monoclonal antibody (clone RED2; dilution 1:150; ZSGB-BIO), a rabbit antiMSH6 monoclonal antibody (clone EP49; dilution 1:200; ZSGB-BIO), and a rabbit anti-PMS2 monoclonal antibody (clone EP51; dilution 1:40; ZSGB-BIO). The tissue sections were counterstained with hematoxylin. Nuclear immunoreactions in lymphocytes, normal colonic mucosa cells or stromal cells within the tissue sections served as internal positive controls. As an external positive control, normal colon tissue was used. The staining of the sections was independently evaluated by two experienced GI pathologists (X.J.F, W.Y.T).

\section{Copy number variations (CNVs) analysis}

Copy number variations (CNVs) were evaluated using the CoNVaDING (Copy Number Variation Detection In Next-generation sequencing Gene panels) tool for detecting single exon CNVs in targeted NGS data [13]. In brief, the pooled raw sequence data were first demultiplexed, extracting reads per sample. For each sample the sequence data were aligned to the human reference genome build 37, as released by the 1000 Genomes project [42], using BWA [43]. The resulting BAM files were utilized for CNV calling and genotyping, and post-processing was performed using CoNVaDING [13]. This algorithm firstly calculates the average depth of coverage for each target, and then selects the control samples showing the most similar coverage pattern from a set of possible control samples based on the match quality control (QC) metric, thereby limiting the sample-tosample variation. In order to obtain a CNV call, the depth of coverage has to differ significantly from the average of two alternative normalizations, using either all (autosomal) targets or all targets belonging to the same gene. CNVs were called by a logical combination of the different ratio score that captures the relative coverage difference between samples and controls, and the distribution score based on a Z-score calculation, which indicates whether a difference is significant or not. QC metrics were calculated for the samples and the targets, making explicit which targets are suitable for analysis with high sensitivity and specificity. Using the target QC values to filter $\mathrm{CNVs}$, high quality calls are separated from calls that are more likely to be false positives.

\section{ACKNOWLEDGMENTS}

We would like to thank Dr. Yan Huang and Dr. Weiyan Tan for help in evaluating the IHC results of the
MMR proteins in the tumor tissues. We also thank the patients for their participation and their cooperation in this study.

\section{CONFLICTS OF INTEREST}

The authors declare that there are no conflicts of interest.

\section{GRANT SUPPORT}

This research has been supported by research grants from the Dutch Cancer Society (KWF, KUN 2015-7740), the Netherlands Organization for Scientific Research (NWO, 91710358), the Royal Dutch Academy of Sciences (KNAW), Guangdong Innovative Research Team Program (2009010058), Guangdong Provincial Department of Science and Technology (2014B020212016), Guangzhou Science Technology and Innovation Commission (2016201604030007), National Key Clinical Discipline and Overseas Excellent Professor Project, Ministry of Education, China, and a scholarship from the China Scholarship Council (CSC) to J Zhang.

\section{REFERENCES}

1. Torre LA, Bray F, Siegel RL, Ferlay J, Lortet-Tieulent J, Jemal A. Global cancer statistics, 2012. CA Cancer J Clin. 2015; 65:87-108.

2. Chen W, Zheng R, Baade PD, Zhang S, Zeng H, Bray F, Jemal A, Yu XQ, He J. Cancer statistics in China, 2015. CA: a cancer journal for clinicians. 2016.

3. Lichtenstein P, Holm NV, Verkasalo PK, Iliadou A, Kaprio J, Koskenvuo M, Pukkala E, Skytthe A, Hemminki K. Environmental and heritable factors in the causation of cancer--analyses of cohorts of twins from Sweden, Denmark, and Finland. The New England journal of medicine. 2000; 343:78-85.

4. de la Chapelle A. Genetic predisposition to colorectal cancer. Nature reviews Cancer. 2004; 4:769-780.

5. Palles C, Cazier JB, Howarth KM, Domingo E, Jones AM, Broderick P, Kemp Z, Spain SL, Guarino E, Salguero I, Sherborne A, Chubb D, Carvajal-Carmona LG, et al. Germline mutations affecting the proofreading domains of POLE and POLD1 predispose to colorectal adenomas and carcinomas. Nature genetics. 2013; 45:136-144.

6. Briggs S, Tomlinson I. Germline and somatic polymerase epsilon and delta mutations define a new class of hypermutated colorectal and endometrial cancers. The Journal of pathology. 2013; 230:148-153.

7. Weren RD, Ligtenberg MJ, Kets CM, de Voer RM, Verwiel ET, Spruijt L, van Zelst-Stams WA, Jongmans MC, Gilissen C, Hehir-Kwa JY, Hoischen A, Shendure J, Boyle EA, et al. A germline homozygous mutation in the 
base-excision repair gene NTHL1 causes adenomatous polyposis and colorectal cancer. Nature genetics. 2015; 47:668-671.

8. Jarvinen HJ, Aarnio M, Mustonen H, Aktan-Collan K, Aaltonen LA, Peltomaki P, De La Chapelle A, Mecklin JP. Controlled 15-year trial on screening for colorectal cancer in families with hereditary nonpolyposis colorectal cancer. Gastroenterology. 2000; 118:829-834.

9. Jarvinen HJ, Renkonen-Sinisalo L, Aktan-Collan K, Peltomaki P, Aaltonen LA, Mecklin JP. Ten years after mutation testing for Lynch syndrome: cancer incidence and outcome in mutation-positive and mutation-negative family members. Journal of clinical oncology. 2009; 27:4793-4797.

10. Nelen M, Veltman JA. Genome and exome sequencing in the clinic: unbiased genomic approaches with a high diagnostic yield. Pharmacogenomics. 2012; 13:511-514.

11. Tao H, Shinmura K, Hanaoka T, Natsukawa S, Shaura K, Koizumi Y, Kasuga Y, Ozawa T, Tsujinaka T, Li Z, Yamaguchi S, Yokota J, Sugimura H, et al. A novel splicesite variant of the base excision repair gene $\mathrm{MYH}$ is associated with production of an aberrant mRNA transcript encoding a truncated MYH protein not localized in the nucleus. Carcinogenesis. 2004; 25:1859-1866.

12. Kim DW, Kim IJ, Kang HC, Jang SG, Kim K, Yoon HJ, Ahn SA, Han SY, Hong SH, Hwang JA, Sohn DK, Jeong SY, Choi HS, et al. Germline mutations of the MYH gene in Korean patients with multiple colorectal adenomas. International journal of colorectal disease. 2007; 22:1173-1178.

13. Johansson LF, van Dijk F, de Boer EN, van DijkBos KK, Jongbloed JD, van der Hout AH, Westers H, Sinke RJ, Swertz MA, Sijmons RH, Sikkema-Raddatz B. CoNVaDING: Single Exon Variation Detection in Targeted NGS Data. Human mutation. 2016; 37:457-464.

14. Hemminki A, Peltomaki P, Mecklin JP, Jarvinen $H$, Salovaara R, Nystrom-Lahti M, de la Chapelle A, Aaltonen LA. Loss of the wild type MLH1 gene is a feature of hereditary nonpolyposis colorectal cancer. Nature genetics. 1994; 8:405-410.

15. de Leeuw WJ, Dierssen J, Vasen HF, Wijnen JT, Kenter GG, Meijers-Heijboer H, Brocker-Vriends A, Stormorken A, Moller P, Menko F, Cornelisse CJ, Morreau H. Prediction of a mismatch repair gene defect by microsatellite instability and immunohistochemical analysis in endometrial tumours from HNPCC patients. The Journal of pathology. 2000; 192:328-335.

16. Shu Z, Yanqin H, Ying Y. Hereditary colorectal cancer in china. Hereditary cancer in clinical practice. 2005; 3:155-164.

17. Umbarger MA, Kennedy CJ, Saunders P, Breton B, Chennagiri N, Emhoff J, Greger V, Hallam S, Maganzini D, Micale C, Nizzari MM, Towne CF, Church GM, et al. Nextgeneration carrier screening. Genet Med. 2014; 16:132-140.

18. O'Roak BJ, Vives L, Fu W, Egertson JD, Stanaway IB, Phelps IG, Carvill G, Kumar A, Lee C, Ankenman K, Munson J, Hiatt JB, Turner EH, et al. Multiplex targeted sequencing identifies recurrently mutated genes in autism spectrum disorders. Science. 2012; 338:1619-1622.

19. Neveling $\mathrm{K}$, Mensenkamp AR, Derks $\mathrm{R}$, Kwint $\mathrm{M}$, Ouchene H, Steehouwer M, van Lier B, Bosgoed E, Rikken A, Tychon M, Zafeiropoulou D, Castelein S, Hehir-Kwa J, et al. BRCA Testing by Single-Molecule Molecular Inversion Probes. Clinical chemistry. 2017; 63:503-512.

20. Eijkelenboom A, Kamping EJ, Kastner-van Raaij AW, Hendriks-Cornelissen SJ, Neveling K, Kuiper RP, Hoischen A, Nelen MR, Ligtenberg MJ, Tops BB. Reliable Next-Generation Sequencing of Formalin-Fixed, ParaffinEmbedded Tissue Using Single Molecule Tags. The Journal of molecular diagnostics. 2016; 18:851-863.

21. Leiden Open Variation Database. URL: http://chromium. lovd.n1/LOVD2. Accessed 16 March, 2016.

22. Hes FJ, Nielsen M, Bik EC, Konvalinka D, Wijnen JT, Bakker E, Vasen HF, Breuning MH, Tops CM. Somatic APC mosaicism: an underestimated cause of polyposis coli. Gut. 2008; 57:71-76.

23. Chubb D, Broderick P, Frampton M, Kinnersley B, Sherborne A, Penegar S, Lloyd A, Ma YP, Dobbins SE, Houlston RS. Genetic Diagnosis of High-Penetrance Susceptibility for Colorectal Cancer (CRC) Is Achievable for a High Proportion of Familial CRC by Exome Sequencing. Journal of Clinical Oncology. 2015; 33:426-432.

24. Zhang JX, Fu L, de Voer RM, Hahn MM, Jin P, Lv CX, Verwiel ETP, Ligtenberg MJL, Hoogerbrugge N, Kuiper RP, Sheng JQ, Geurts van Kessel A. Candidate colorectal cancer predisposing gene variants in Chinese early-onset and familial cases. World Journal of Gastroenterology. 2015; 21:4136-4149.

25. Tanskanen T, Gylfe AE, Katainen R, Taipale M, RenkonenSinisalo L, Mecklin JP, Jarvinen H, Tuupanen S, Kilpivaara O, Vahteristo P, Aaltonen LA. Exome sequencing in diagnostic evaluation of colorectal cancer predisposition in young patients. Scandinavian journal of gastroenterology. 2013; 48:672-678.

26. Li D, Hu F, Wang F, Cui B, Dong X, Zhang W, Lin C, Li X, Wang D, Zhao Y. Prevalence of pathological germline mutations of hMLH1 and hMSH2 genes in colorectal cancer. PLoS One. 2013; 8:e51240.

27. Liu F, Yang L, Zhou X, Sheng W, Cai S, Liu L, Nan P, $\mathrm{Xu}$ Y. Clinicopathological and genetic features of Chinese hereditary nonpolyposis colorectal cancer (HNPCC). Med Oncol. 2014; 31:1-7.

28. Yang L, Ding YQ, Li GX, Yu J, Wang Y, Zhou J, Yang HJ, Zhang JH. [Microsatellite analysis and hMLH1/hMSH2 expression detection in young patients with colorectal cancer: value in screening hereditary nonpolyposis colorectal cancer]. [Article in Chinese]. Nan fang yi ke da xue xue bao. 2007; 27:779-782.

29. Jin HY, Liu X, Li VK, Ding Y, Yang B, Geng J, Lai R, Ding S, Ni M, Zhao R. Detection of mismatch repair gene 
germline mutation carrier among Chinese population with colorectal cancer. BMC cancer. 2008; 8:44.

30. Wei W, Liu F, Liu L, Li Z, Zhang X, Jiang F, Shi Q, Zhou X, Sheng W, Cai S, Li X, Xu Y, Nan P. Distinct mutations in MLH1 and MSH2 genes in hereditary non-polyposis colorectal cancer (HNPCC) families from China. BMB reports. 2011; 44:317-322.

31. Fu L, Sheng JQ, Sun ZQ, Han M, Huang JS, Mu H, Han WL, Niu HL, Li AQ, Wu ZT, Li SR. [Mutation of hMLH1 and hMSH2 genes in hereditary nonpolyposis colorectal cancer: analysis of 76 probands]. [Article in Chinese]. Zhonghua Yi Xue Za Zhi. 2008; 88:1983-5.

32. Cai Q, Sun MH, Fu G, Ding CW, Mo SJ, Cai SJ, Ren SX, Min DL, Xu XL, Zhu WP, Zhang TM, Shi DR. [Mutation analysis of hMSH2 and hMLH1 genes in Chinese hereditary nonpolyposis colorectal cancer families]. [Article in Chinese]. Zhonghua Bing Li Xue Za Zhi. 2003; 32:323-8.

33. Al-Tassan N, Chmiel NH, Maynard J, Fleming N, Livingston AL, Williams GT, Hodges AK, Davies DR, David SS, Sampson JR, Cheadle JP. Inherited variants of MYH associated with somatic G:C-->T:A mutations in colorectal tumors. Nature genetics. 2002; 30:227-232.

34. Ligtenberg MJ, Kuiper RP, Geurts van Kessel A, Hoogerbrugge N. EPCAM deletion carriers constitute a unique subgroup of Lynch syndrome patients. Familial cancer. 2013; 12:169-174.

35. Boyle EA, O'Roak BJ, Martin BK, Kumar A, Shendure J. MIPgen: optimized modeling and design of molecular inversion probes for targeted resequencing. Bioinformatics. 2014; 30:2670-2672.

36. Hiatt JB, Pritchard CC, Salipante SJ, O'Roak BJ, Shendure J. Single molecule molecular inversion probes for targeted, high-accuracy detection of low-frequency variation. Genome research. 2013; 23:843-854.

37. Pollard KS, Hubisz MJ, Rosenbloom KR, Siepel A. Detection of nonneutral substitution rates on mammalian phylogenies. Genome research. 2010; 20:110-121.

38. Kumar P, Henikoff S, Ng PC. Predicting the effects of coding non-synonymous variants on protein function using the SIFT algorithm. Nature protocols. 2009; 4:1073-1081.

39. Adzhubei IA, Schmidt S, Peshkin L, Ramensky VE, Gerasimova A, Bork P, Kondrashov AS, Sunyaev SR. A method and server for predicting damaging missense mutations. Nature methods. 2010; 7:248-249.

40. Kircher M, Witten DM, Jain P, O'Roak BJ, Cooper GM, Shendure J. A general framework for estimating the relative pathogenicity of human genetic variants. Nature genetics. 2014; 46:310-315.

41. Untergasser A, Cutcutache I, Koressaar T, Ye J, Faircloth BC, Remm M, Rozen SG. Primer3--new capabilities and interfaces. Nucleic acids research. 2012; 40:e115.

42. Genomes Project C, Abecasis GR, Altshuler D, Auton A, Brooks LD, Durbin RM, Gibbs RA, Hurles ME, McVean GA. A map of human genome variation from population-scale sequencing. Nature. 2010; 467:1061-1073.
43. Li H, Durbin R. Fast and accurate short read alignment with Burrows-Wheeler transform. Bioinformatics. 2009; 25:1754-1760.

44. Fokkema IF, Taschner PE, Schaafsma GC, Celli J, Laros JF, den Dunnen JT. LOVD v.2.0: the next generation in gene variant databases. Human mutation. 2011; 32:557-563.

45. Ou J, Niessen RC, Vonk J, Westers H, Hofstra RM, Sijmons RH. A database to support the interpretation of human mismatch repair gene variants. Human mutation. 2008; 29:1337-1341.

46. Landrum MJ, Lee JM, Riley GR, Jang W, Rubinstein WS, Church DM, Maglott DR. ClinVar: public archive of relationships among sequence variation and human phenotype. Nucleic acids research. 2014; 42:D980-985.

47. Thompson BA, Spurdle AB, Plazzer JP, Greenblatt MS, Akagi K, Al-Mulla F, Bapat B, Bernstein I, Capella G, den Dunnen JT, du Sart D, Fabre A, Farrell MP, et al. Application of a 5-tiered scheme for standardized classification of 2,360 unique mismatch repair gene variants in the InSiGHT locus-specific database. Nature genetics. 2014; 46:107-115.

48. National Comprehensive Cancer Network I. The NCCN Clinical Practice Guidelines in OncologyTM Genetic/ Familial High-Risk Assessment: Colorectal V2.2014. (http://www.nccn.org/). 2014.

49. Burt RW, Leppert MF, Slattery ML, Samowitz WS, Spirio LN, Kerber RA, Kuwada SK, Neklason DW, Disario JA, Lyon E, Hughes JP, Chey WY, White RL. Genetic testing and phenotype in a large kindred with attenuated familial adenomatous polyposis. Gastroenterology. 2004; 127:444-451.

50. Jasperson KW. Genetic testing by cancer site: colon (polyposis syndromes). Cancer journal. 2012; 18:328-333.

51. Samadder NJ, Jasperson K, Burt RW. Hereditary and common familial colorectal cancer: evidence for colorectal screening. Digestive diseases and sciences. 2015; 60:734-747.

52. Aarnio M, Sankila R, Pukkala E, Salovaara R, Aaltonen LA, de la Chapelle A, Peltomaki P, Mecklin JP, Jarvinen HJ. Cancer risk in mutation carriers of DNA-mismatch-repair genes. International journal of cancer. 1999; 81:214-218.

53. Hampel H, Stephens JA, Pukkala E, Sankila R, Aaltonen LA, Mecklin JP, de la Chapelle A. Cancer risk in hereditary nonpolyposis colorectal cancer syndrome: later age of onset. Gastroenterology. 2005; 129:415-421.

54. Watson P, Vasen HF, Mecklin JP, Bernstein I, Aarnio M, Jarvinen HJ, Myrhoj T, Sunde L, Wijnen JT, Lynch HT. The risk of extra-colonic, extra-endometrial cancer in the Lynch syndrome. International journal of cancer. 2008; 123 : 444-449.

55. Stoffel E, Mukherjee B, Raymond VM, Tayob N, Kastrinos F, Sparr J, Wang F, Bandipalliam P, Syngal S, Gruber SB. Calculation of risk of colorectal and endometrial cancer among patients with Lynch syndrome. Gastroenterology. 2009; 137:1621-1627.

56. Capelle LG, Van Grieken NC, Lingsma HF, Steyerberg EW, Klokman WJ, Bruno MJ, Vasen HF, Kuipers EJ. Risk and 
epidemiological time trends of gastric cancer in Lynch syndrome carriers in the Netherlands. Gastroenterology. 2010; 138:487-492.

57. Baglietto L, Lindor NM, Dowty JG, White DM, Wagner A, Gomez Garcia EB, Vriends AH, Dutch Lynch Syndrome Study G, Cartwright NR, Barnetson RA, Farrington SM, Tenesa A, Hampel H, et al. Risks of Lynch syndrome cancers for MSH6 mutation carriers. Journal of the National Cancer Institute. 2010; 102:193-201.

58. Jenkins MA, Croitoru ME, Monga N, Cleary SP, Cotterchio M, Hopper JL, Gallinger S. Risk of colorectal cancer in monoallelic and biallelic carriers of $\mathrm{MYH}$ mutations: a population-based case-family study. Cancer epidemiology, biomarkers \& prevention : a publication of the American Association for Cancer Research, cosponsored by the American Society of Preventive Oncology. 2006; $15: 312-314$.
59. Rennert G, Lejbkowicz F, Cohen I, Pinchev M, Rennert HS, Barnett-Griness O. MutYH mutation carriers have increased breast cancer risk. Cancer. 2012; 118:1989-1993.

60. Win AK, Cleary SP, Dowty JG, Baron JA, Young JP, Buchanan DD, Southey MC, Burnett T, Parfrey PS, Green RC, Le Marchand L, Newcomb PA, Haile RW, et al. Cancer risks for monoallelic MUTYH mutation carriers with a family history of colorectal cancer. International journal of cancer. 2011; 129:2256-2262.

61. Vogt S, Jones N, Christian D, Engel C, Nielsen M, Kaufmann A, Steinke V, Vasen HF, Propping P, Sampson JR, Hes FJ, Aretz S. Expanded extracolonic tumor spectrum in MUTYH-associated polyposis. Gastroenterology. 2009; 137:1976-1985 e1971-1910. 